\title{
Capacity Building, Human Resource Development (HRD) and Bahrainisation: Perceptions of Senior Public Sector Employees in Bahrain
}

\author{
La'aleh Alaali, Arab Open University, Bahrain \\ Christopher J. Rees, Global Development Institute, \\ University of Manchester, $U K$
}

\begin{abstract}
This paper reports the findings of Phase 2 of the study, initially reported upon in this journal in 2018 (Alaali \& Rees, 2018), and in which we explored the association between Capacity Building and HRD. In Phase 2 of the study, we use the case of Bahrain's nationalization programme (Bahrainisation) to examine the perceptions of senior government employees towards Capacity Building and HRD. A total of 20 senior government officials were interviewed in order to ascertain their views about the links between Capacity Building and HRD and also the factors which they consider to be critical to the outcomes of the nationalization programme. The findings reveal that the interviewees viewed HRD activities to be an integral element of national Capacity Building. These practitioners also identified the important role of lifelong development activities such as education and training in Capacity Building. Further, in findings which complement the conclusions drawn in Phase 1 of the study, it was found that the interviewees emphasized sustainability and national level considerations, such as legislation and occupational standards, as integral features of Capacity Building as opposed to HRD. In contrast to Phase 1, the interview data also drew attention to the importance the interviewees placed on research data to inform Capacity Building initiatives at the national level. These findings are discussed with reference to subjects such as the inter-disciplinary nature of Capacity Building and HRD and also emergent work on evidence-based practice.
\end{abstract}

Key Words: Capacity Building, human resource development, nationalization; Bahrain, Bahrainisation

\section{Introduction}

In an earlier paper published in this Journal (Alaali \& Rees, 2018), we examined, primarily from a theoretical position, the relationship between 'Human Resource Development' (HRD) and 'Capacity Building'. In that paper, which constituted Phase 1 of this research, we compared and contrasted published definitions and descriptions of these terms and, in doing so, drew attention to a number of potential intersections that exist between Capacity Building and HRD in areas such as performance and development. On the basis of the findings, we concluded that HRD can be considered as a development process which has a role to play in broader Capacity Building initiatives particularly in non-Western international development contexts.

The current paper reports the findings of Phase 2 of the research in which we explore further the nature of the role of HRD in Capacity Building from a more applied perspective in a nonWestern international context, that is, Bahrain. The main purpose of this research is to use the 
case of Bahrain's nationalization programme to examine the perceptions of practitioners, that is, senior government employees towards Capacity Building and HRD with view to shedding further light on the relationship between these terms.

The paper is structured as follows. In the first sections of the paper, we consider the overall purpose and nature of nationalization strategies in the Middle East and specifically in Bahrain. Two research questions are then presented which are addressed using the findings of interviews undertaken with 20 senior government employees in Bahrain. In the final section of the paper we highlight conclusions linked to Capacity Building and HRD in this applied context.

\section{Nationalization Strategies in the Middle East}

One of the key reasons why the context of the Middle East is particularly relevant to discussions surrounding Capacity Building and HRD is because of the nationalization strategies which have been implemented throughout the States of the Gulf Cooperation Council (GCC) (Forstenlechner, 2010; Marchon \& Toledo, 2014; Mellahi \& Al-Hinai, 2000). These nationally devised Capacity Building strategies, such as Bahrainisation, Emiratisation, Saudisation, and Omanisation, are intended to reduce reliance on expatriate labour by developing the local workforce and providing employment opportunities in the private sector for members of the indigenous population (Rees et al., 2007; Jabeen et al., 2018). While recognizing the view that, in the GCC: "sustainable and competitive growth of individual states is increasingly taking precedence" (Hayes \& Findlow, 2017, p. 4), it is highlighted that nationalization strategies across the region have a number of common features. These features include: “... imposed quotas for the employment of nationals, education and training systems to improve the employability of nationals, and attractive incentive schemes for companies which adhere to nationalization policies" (Alaali \& Rees, 2016, p. 76). The next section of the discussion considers further the nature of nationalization and its links to Capacity Building and HRD by highlighting governmental initiatives associated with the nationalization strategy in Bahrain.

\section{Nationalization in Bahrain}

The 1998 United Nations Development Programme (UNDP) identified Bahrain as the first State in the Middle East to initiate a comprehensive debate about labour market reforms as indicated by the Bahrainisation programme which was initiated in the early 1980s (Hertog, 2014). In the early years of the programme, the government of Bahrain recognized various challenges in implementing its nationalization strategy including: "a lack of awareness and commitment of employers, inadequate labour inspection and employment services; and limited capacity of the training system" (ILO, 2002, p. 33) As a result, various government entities were created and others charged with undertaking responsibilities linked to the nationalization strategy. The nature and responsibilities of these organizations offer further insights into how the government has approached national Capacity Building through Bahrainisation.

First, the Ministry of Labour (MOL), whose vision is "Enhancing the National Human Resources in a sustained organized Labour Market", was charged with the responsibility of reforming the labour market to ensure that, through legislation, regulation, and training opportunities, Bahraini nationals could participate more fully in all sectors of the economy. 
Second, the government set up Tamkeen, a semi-government authority which has a stated vision of: "Empowering Bahrainis to prosper and contribute to the national economy" and a mission which includes: "Making Bahrainis the employee of choice for semi-skilled professions". Tamkeen's role is to assist government strategies towards the achievement of Bahrain's 2030 Economic Vision and National Strategy through effective human capital development and the optimization of talent among the indigenous workforce (Tamkeen, 2018).

Third, the Labour Market and Regulatory Affairs (LMRA) is a government entity which has the stated vision: "to interact with the society through linear and direct partnership to provide high quality services beyond local market expectations". The LMRA is formally responsible for providing solutions and services to the local market to deliver: "judicious labour market policies, manage an effective and humane expatriate labour market programme, and provides efficient application of the law" (LMRA, 2019).

Fourth, the Ministry of Education in Bahrain has a strategy to develop human resources by improving the education process through accessible, responsive, high quality education oriented services for the public. In its vision the Ministry:

seeks to develop a qualitative education system to reach a high degree of excellence and creativity. This vision emanates from the Islamic Religion lofty principles and values and the Kingdom of Bahrain's interaction with the human civilization and its Arab belonging to satisfy the requirements of continuous development that conforms with the international standards, as stated in the Kingdom's constitution (Ministry of Education, Kingdom of Bahrain, 2019).

Fifth, the Quality Assurance Authority for Education and Training (BQA) was set up with a vision: "To be leaders in fostering sustainable quality enhancement for world-class education and training sectors in Bahrain". The BQA is responsible for reviewing public and private schools, vocational training and higher education institutions, developing and implementing a national examination system for schools, and advancing Bahrain's reputation as a leader in quality assurance in education, regionally and internationally (BQA, 2019).

These five entities remain actively involved in addressing various challenges associated with the nationalization programme. These challenges relate to the economic and societal cost of unemployment, the quality of life experienced by Bahrainis, the perceptions of Bahrainis by private sector employers, problematic career management at the individual level, and inadequate training opportunities for Bahrainis. Nevertheless, despite the efforts ploughed into Bahrainisation by such government entities, Ewers et al. (2018, p. 10) point out that: “... Bahrain remains heavily dependent on foreign labour due to inadequate local human capital ... Bahrain's local population constitutes $21 \% \ldots$ of the total workforce". Given these types of ongoing challenges, further research involving senior practitioners in the public sector who hold responsibilities for implementing this national policy may offer real insights into how Capacity Building and HRD are viewed.

\section{Research Questions}

Senior government employees employed in various government entities in Bahrain are engaged in Capacity Building initiatives at both national and local levels. Yet, despite the involvement of government entities and officials in the implementation of nationalization strategies, there is a 
dearth of studies which have explored the views of senior government employees towards the role and integration of HRD within these centrally-devised Capacity Building strategies. As such, the Kingdom of Bahrain offers a real opportunity to undertake contextualized research which sheds further light on the relationship between Capacity Building and HRD from a national rather than organizational perspective. Hence, from the perspectives of senior government employees, Phase 2 of this research addressed two research questions with reference to the context of Bahrain.

1. To what extent is HRD linked with Capacity Building?

2. What critical factors are associated with the implementation of Capacity Building programmes in applied contexts?

Answers to the research questions stated above are likely to be highly relevant to theoretical debates about the relationship between HRD and Capacity Building and also to be of interest to those involved with nationalization programmes in Bahrain and perhaps more widely in the GCC region.

\section{Methodology}

In order to address the research questions, semi-structured interviews were conducted with 20 senior government officials working in human capital development in four government organizations in Bahrain, namely: the Ministry of Labour (six interviewees); Tamkeen (six interviewees); the Labour Market Regulatory Authority (two interviewees); and the Quality Assurance Authority (BQA) (six interviewees). The interviewees (nine males and eleven females) were employed in roles such as directors, department heads, and section managers.

The semi-structured questions were structured around the following areas of interest which were identified in the literature reviewed as part of this study (see also Alaali \& Rees, 2018): nationalization and HRD practices; building capacities through nationalization; and critical factors associated with Capacity Building. To ensure the validity of data collected, the semistructured interviews were recorded electronically with the consent of the interviewees and in accordance with the ethics approval procedures of a Higher Education institution within the UK. The interviews were conducted in English and the resulting interview data were analyzed using software to identify principal themes which were used to create a thematic map.

\section{Findings}

\section{Research Question 1: the Link Between Capacity Building and HRD}

When the interviewees were asked, in general terms, about their employers' involvement with the Bahrainisation programme, one of the findings to emerge at an early stage of the interviews was the extent to which this group of practitioners linked Capacity Building to HRD activities such as skills development, training, and career development. For example:

Building capacities in the economy of Bahrain is being done by developing a skills gap strategy to reduce the mismatch between the outcomes of the university and market needs. Gulf Aviation 
Academy is an example where we gave the business model to Mumtalakat, money stays in our economy, and training is done in Bahrain to serve Bahrain and GCC. We are currently trying to build capacities for cabin crew, transport and logistics (Vice President Human Capital Development).

Results of our trainings will accumulate overtime where at the end you will have a result of a pool of skilled Bahrainis in certain areas (logistics, aviation). This form of capacities [is] a dramatic shift from the regular fields of interest as it was built up through studies and surveys showing there is a need in the economy. We will have to wait a period of time to assess the capacities built through Tamkeen training (Manager Planning and Business Development).

The career progression programme (CPP) in Bahrain generates capacities as it develops and trains nationals to be placed in the private sector (Manager Human Capital Development).

This association between Capacity Building and HRD activities was further evident when the interviewees were asked to elaborate on how their organizations were contributing to the nationalization agenda. For example, respondents from Tamkeen highlighted that the organization provides various training schemes which are given Arabic names in order to attract the interest of nationals. These schemes are designed to build capacities within the economy for entrepreneurship projects for the enhancement of professional skills for business. In the words of one respondent:

We offer the ehtref [meaning 'get skilled' in Arabic] scheme open for any national to get a professional certification, as nationals require development on professional sides to build their capabilities for the economy. In addition, we have the mashroay [meaning 'my project' in Arabic] scheme that builds entrepreneurship capacities by nurturing idea generators and start up initiatives (Senior Manager 1 Human Capital Development).

Similarly, the Ministry of Labour was cited as playing a role in formulating policies and strategies for training and development within the private sector.

\section{The relationship between Capacity Building and HRD}

When asked to respond more specifically to questions about the relationship between HRD activities and Capacity Building, activities such as training and development were often characterized as generators of Capacity Building and many of the interviewees indicated the importance of HRD within Bahrainization strategies:

Capacity Building cannot be ignored - its marvel is in the center of the HRD strategy. HRD is not the full story. Capacity Building is at the heart of HRD at all levels (Training Affairs Advisor).

Ministry of Labour activities are the heart of HRD for Bahrain. We have the Training and Development sector, Labor Affairs sectors, Inspection sector that aim to build capabilities in nationals (Head of Labor Inspection Department).

Each group in the labour market has a certain capacity to meet market needs. An industry set by the government shall sustain people through human resource development activities and will blossom. In this way management maintains good people by formation of career development (Manager Policy Development).

\section{The role of lifelong development activities in Capacity Building}

The responses obtained from the interviewees reflect that both education and training were seen by the respondents, without exception, to play a crucial developmental role in Capacity 
Building at the national level. Development activities included, for example, both vocationallyoriented training and also education in institutions and schools designed to ensure that Bahrainis become 'employees of choice', as described by some of the government officials. The following interview statements support the above analysis:

For Capacity Building we train institutes in terms of Capacity Building. But we do not have something prescribed, it is a general process. We improve education, institutes, and skills of Bahrainis which is all linked with the 2030 Bahraini vision to make a 'Bahraini first choice' for private sector employers (Manager 1 Higher Education Unit).

We do Capacity Building activities through quality reviewers to visit educational and training institutes to build the knowledge, skills and abilities up to international standards (Manager 2 Higher Education Unit).

We look at the personal development of students and provision for development for better quality outcomes in terms of knowledge, skills and abilities. Before we used to measure success percentages but this does not have a skills factor that we need for our economy (Head of School Review Unit).

Notably, in the above indicative quotes, the use of terms such as train; develop; knowledge; skills; abilities; assessing skills gap; personal development and training again reveals the direct association which the interviewees made between Capacity Building and HRD activities.

\section{Research Question 2: Implementing Capacity Building in Applied Contexts}

In the light of their involvement with Capacity Building associated with the Bahrainisation programme, the interviewees were asked to identify factors which, in their opinion, are critical to the successful implementation of Capacity Building initiatives at the national level. Two key factors emerged from the interview data.

\section{The need for research/intelligence-informed Capacity Building}

In response to questions about critical success factors associated with Capacity Building, the majority of the interviewees raised the importance of devising policies and programmes which are informed by research/intelligence. Using the indicative words of two of the respondents:

Our issue is we do not have access towards reliable data. We need data about our economic needs to direct Bahrainis towards trainings and development that have sectors to absorb them. We face an issue of data collection as government entities did not collect data for a long time (Senior Manager 1 Human Capital Development).

There is no solid base for jobs categorization. We need an IT support system [a] fully fledged system to categorize specializations to actually indicate the manpower required to build capacities in sectors (Director of Training Institutes Affairs).

Other respondents went further and talked about the need for a unit or organization which is dedicated to gathering and providing information which could be used to inform Capacity Building initiatives. For example:

The intelligence unit is required to identify the market and economic requirements for coming periods in Bahrain. It is essential to have such a unit to prepare nationals' skills for clearly-identified gaps in the labour market (Manager Planning and Business Development). 
We need an intelligence unit to generate data at a regular basis to assess skills gap and be responsible to generate ongoing data regarding the skills gap as it keeps on changing with years. This will form a compass that will direct entities towards Capacity Building (Senior Manager 2 Human Capital Development).

As can be seen from the above quotes, this emphasis on the need for research/intelligence to inform nationalization activities tends to highlight national issues such as economic requirements, the labour market and skills gaps. This finding relates directly to issues discussed in Phase 1 of the research (Alaali \& Rees, 2018, pp. 28-29) which identified potential points of intersection between Capacity Building and HRD, such as their multi-level foci and their engagement with economic theory and development.

\section{Sustainability}

The interviews also identified sustainability as a second critical factor associated with the implementation of Capacity Building programmes in Bahrain. That is, the majority of the interviewees explicitly expressed the view that sustainability is required to gain the benefits from investment in Capacity Building in the form of Bahrainisation. For example:

We find deficiency in Capacity Building as strategies in the actual economy are not joined. Government entities need to work together and coordinate for sustainable projects towards national recruitment. For example, being the main recruitment entity, MOL and Industry of Commerce need to form joint projects to bridge the gap in bringing foreign trade and giving a time frame for utilizing expatriate competencies. After that nationals take over the positions from a pool of accredited Bahraini nationals to strengthen Capacity Building (Head of Labor Inspection Department).

Strategies need to work towards sustaining sectors. Nationalization strategies in Bahrain are contradicting as well. There is flexibility for foreign business, providing freedom for employing foreigners to support the business and we end up losing developed national human resources by having a liberating foreign investment (Manager Policy Development).

In addition to calling for effective collaboration among government entities, the majority of the interviewees identified nationally-determined occupational standards, policies and laws as a means to sustain the nationalization agenda:

The problem is not with the nationals but with our labour laws and sectors itself. There are no occupational skills standards or laws that govern these sectors. We do not have occupational skills standards in any sector. The solutions which are needed include legislation, occupational skills standards and coordination among entities. Then there will be industry standards, certifications, training packages, and defined pay skill, with that we can succeed with sustaining sectors through nationals (Manager Human Capital Development).

A holistic solution to tackle Bahrainisation from all sides is required for Capacity Building. We need to have occupational standards to make Bahrainis as competent as expatriates. We need to make Bahrainis to be the employers' first choice. We are currently working on several initiatives to make the employer attractive. And we are coming up with award schemes. Tax on expatriates is required; this will act as a sweetener to encourage employers to take on Bahraini workers (Senior Manager Human Capital Development).

Phase 1 of this research (Alaali \& Rees, 2018) found that the issue of sustainability tended to be emphasized more strongly in definitions and descriptions of Capacity Building than in HRD literature. Notably, in this more applied context of Phase 2 of the research, the interviewees also tended to link sustainability to Capacity Building rather than to HRD activities: 
Human Resource Development is practiced in Bahrain but sustainable developments are lacking. Occupational level standards can create sustainability and this can be done through categorization of jobs through a license and this categorization needs to be practical as well. But we are working randomly. We need organized trainings through the job categorization and change the way of training and make it more practical to sustain sector and individual growth (Director of Training Institutes Affairs).

... we are providing various forms of training and development programmes giving a stepping stone to youth, but not the skills to sustain a certain sector. We are serving everybody even school dropout but we have not done a sector specific human capital enrichment to be surely sustainable for that sector. Foreign direct investment, more institutions, more entrepreneurs, national apprenticeship schemes and refined policies in the labour market are required to be looked at by the government for sustainability (Vice President Human Capital Development).

Thus, as indicated by the quotes above, a number of the interviewees stated that even though HRD activities were taking place as part of nationalization initiatives, the Capacity Building programme, as a whole, was seen to be wanting in the area of sustainability.

\section{Conclusion}

Phase 1 of the study examined academic literature to consider the relationship between Capacity Building and HRD from theoretical perspectives. Specifically from Phase 2 we report the findings of interviews with senior government officials in Bahrain in which we asked them questions about the relationship between Capacity Building and HRD, and the critical success factors associated with the Capacity Building nationalization programme. It is evident that the interviewees viewed HRD activities such as training and development, education, and career development as integral to the Capacity Building Bahrainisation programme. As such, these findings support the findings of Phase 1 of the study in drawing attention to the inextricable links that exist between Capacity Building and HRD. What is also evident from the findings is that the interviewees differentiated Capacity Building from HRD when they identified sustainability as a critical success factor associated with the nationalization programme. That is, the findings reveal that interviewees recognized HRD activities were taking place but that these activities were not wholly effective because there were problems with the sustainability of the Capacity Building programme. This finding is entirely consistent with the findings of Phase 1 of the study which identified sustainability as an issue which tended to be more strongly emphasized in Capacity Building literature than in HRD literature.

The findings of both Phase 1 and Phase 2 have consistently indicated that HRD can be considered as a development process which has a role to play in broader Capacity Building initiatives. Specifically, the findings of Phase 2 helpfully highlight that these broader national Capacity Building initiatives may need to involve consideration of issues such as national occupational standards, qualifications, the national labour market and its regulation, and collaborations and partnerships between government agencies. Thus, while Phase 1 of the study found that, from theoretical perspectives, both HRD and Capacity Building have various levels of analyses (that is, national, institutional, organizational, and individual) which feature in their definitions, Phase 2 of the study has identified specific examples of national and institutional Capacity Building considerations that practitioners in Bahrain highlighted as relevant to the nationalization Capacity Building programme. 
Phase 2 has also highlighted that these senior government practitioners in Bahrain placed a high value on the need for Capacity Building at the national level to be informed by research/ intelligence-generated data. This emphasis which practitioners placed upon the need for data in devising strategies at the national, sector and local levels, did not emerge as a clear theme in the literature reviewed in Phase 1 of the study. As such, this finding suggests that this is an issue which researchers may consider as a fruitful area for future research. This type of research would build on the emerging body of literature on evidence-based practice (Hamlin, 2016; Wright et al., 2016) and could be used to inform policy and practice relating to both Capacity Building and HRD.

Finally, the interview data collected from Bahrain complemented the literature review analysis presented in Phase 1 by emphasizing the complexity and inter-disciplinary nature of Capacity Building and HRD initiatives in an applied developing country context. This observation highlights that those responsible for national Capacity Building and HRD initiatives should be seeking to engage with national development policies and frameworks in order to ensure that policies, strategies and projects are both informed by and complementary to other national and local agendas and activities.

\section{References}

Alaali, L., \& Rees, C. J. (2016). Nationalization Strategies in the Gulf Co-operation Council (GCC) Countries: A Human Resource Development (HRD) Perspective. In J. Bawole, F. Hossain, A. Ghalib, C. J. Rees, \& A. Mamman (eds), Development Management in Developing and Transitional Countries: Theory and Practice. Routledge, Abingdon, Oxon, 75-87.

Alaali, L. \& Rees C. J. (2018). Sustainability, Performance and Development: Towards an Understanding of the Intersections Between Human Resource Development (HRD) and Capacity Building. International Journal of Human Resource Development Policy Practice and Research, 3(2), 23-34.

BQA (2019). The Education and Training Quality Authority: Vision Mission and Values. Manama: BQA. Available from: http://www.bqa.gov.bh/En/AboutQaaet/Pages/vision_mission.aspx [Accessed 6th March, 2019]

Ewers, M. C., Dicce, R., Poon, J., Chow. J., \& Gengler, J. (2018). Creating and Sustaining Islamic Financial Centers: Bahrain in the Wake of Financial and Political Crises, Urban Geography, 39(1), 3-25.

Forstenlechner, I. (2010). Workforce Localisation in Emerging Gulf Economies: The Need to Fine-Tune HRM. Personnel Review, 39(1), 135-52.

Hamlin, B. (2016). HRD and Organisational Change: Evidence Based Practice, International Journal of Human Resource Development Practice, Policy and Research, (1), 7-20.

Hayes, A., \& Findlow, S. (2017). The Role of Time in Policymaking: A Bahraini Model of Higher Education Competition, Critical Studies in Education, DOI: 10.1080/17508487.2017.1358756

Hertog, S. (2014). Arab Gulf States: An Assessment of Nationalisation Policies. GLMM Research Paper No. 1/2014. Cambridge: European University Institute and Gulf Research Centre.

ILO (2002). Employment, Social Protection and Social Dialogue: An Integrated Policy Framework for Promoting Decent Work in Bahrain. Geneva: ILO. Available from: https://www.ilo.org/public/english/ bureau/dwpp/download/bahrain/bah2002.pdf [Accessed 6th March 2019]

Jabeen, F., Faisal, M. N., \& Katsioloudes, M. (2018). Localisation in an Emerging Gulf Economy: Understanding the Role of Education, Job Attributes and Analysing the Barriers in its Process, Equality, Diversity and Inclusion: An International Journal, 37(2), 151-166.

LMRA (2019). The Labour Market Regulatory Authority: Our Mandate. Manama: LMRA. Available from: http://lmra.bh/portal/en/page/show/56 [Accessed 6th March 2019]

Marchon, C., \& Toledo, H. (2014). Re-thinking Employment Quotas in the UAE, The International Journal of Human Resource Management, 25(16), 2253-2274. 
Mellahi, K., \& Al-Hinai, S. M. (2000). Local Workers in Gulf Co-operation Countries: Assets or Liabilities, Middle Eastern Studies, 36(3), 177-90.

Ministry of Education of the Kingdom of Bahrain (2019). Ministry of Education: Mission and Vision. Manama: Ministry of Education Bahrain. Available from: http://www.moe.gov.bh/vision_mission. aspx?lan=en [Accessed March 3rd 2019]

Rees, C. J., Mamman, A., \& Bin Braik, A. (2007). Emiratisation as a Strategic HRM Change Initiative: Case Study Evidence from a UAE Petroleum Company. The International Journal of Human Resource Management, 18(1), 33-53.

Tamkeen (2018). Empowering Bahrainis to Prosper and Contribute to the Growth of the National Economy. Manama: Tamkeen. Available from: https://www.tamkeen.bh/missionandvision [Accessed 6th March 2018]

Wright, A. L., Zammuto, R. F., Liesch, P. W., Middleton, S., Hibbert, P., \& Burke, J. (2016). Evidencebased Management in Practice: Opening up the Decision Process, Decision-maker and Context, British Journal of Management, 27(1), 161-178.

\section{The Authors}

Dr La'aleh Al-Aali is an Assistant Professor in the Business Administration Systems (BAS) programme in the Arab Open University (AOU), Bahrain. Apart from teaching, she is the branch course coordinator for the Level 3 modules within the programme and holds the overall BAS program coordination and management. Before joining the academic field in 2014, she was a HR professional for ten years in the areas of learning, development, and organisational change management within the Telecom, Petroleum, and FMCG sector in Bahrain. She is an external verifier for CIPD Level 5 and Level 7 for the Bahrain Institute of Banking and Finance and supervises Master level dissertations for the distance programme of HRM in the University of Manchester.

Dr Chris Rees is a Senior Lecturer in Human Resources and Organisational Change at the Global Development Institute (GDI), University of Manchester, UK. He is a Chartered Psychologist and a Chartered Fellow of the CIPD. Prior to commencing full-time academic work, he held senior positions in the public and financial services sectors in the UK. Chris has published widely in a range of international journals including the Journal of Business Ethics, the International Journal of Human Resource Management, Human Resource Development International and the Journal of Organisational Change Management. 